\title{
The North Atlantic as a Driver of Summer Atmospheric Circulation
}

\author{
JOE M. OSBORNE \\ Met Office, Exeter, United Kingdom \\ Mat Collins, James A. ScReen, AND STEPhen I. Thomson \\ College of Engineering, Mathematics and Physical Sciences, University of Exeter, Exeter, United Kingdom \\ Nick Dunstone \\ Met Office Hadley Centre, Exeter, United Kingdom
}

(Manuscript received 7 June 2019, in final form 3 May 2020)

\begin{abstract}
Skill in seasonal forecasts in the Northern Hemisphere extratropics is mostly limited to winter. Drivers of summer circulation anomalies over the North Atlantic-European (NAE) sector are poorly understood. Here, we investigate the role of North Atlantic sea surface temperatures (SSTs) in driving summer atmospheric circulation changes. The summer North Atlantic Oscillation (SNAO), the leading mode of observed summer atmospheric circulation variability in the NAE sector, is correlated with a distinct SST tripole pattern in the North Atlantic. An atmospheric general circulation model is used to test whether there are robust atmospheric circulation responses over the NAE sector to concurrent SSTs related to the SNAO. The most robust responses project onto the summer east Atlantic (SEA) pattern, the second dominant mode of observed summer atmospheric circulation variability in the NAE sector, and are most evident at the surface in response to tropical SSTs and at altitude in response to extratropical SSTs. The tropical-to-extratropical teleconnection appears to be due to Rossby wave propagation from SST anomalies, and in turn precipitation anomalies, in the Caribbean region. We identify key biases in the model, which may be responsible for the overly dominant SEA pattern variability, compared to the SNAO, and may also explain why the responses resemble the SEA pattern, rather than the SNAO. Efforts to eradicate these biases, perhaps achieved by higher-resolution simulations or with improved model physics, would allow for an improved understanding of the true response to North Atlantic SST patterns.
\end{abstract}

\section{Introduction}

Building on skillful predictions at seasonal time scales in the tropics (Kumar et al. 2013), recent years have seen considerable advances in the understanding of drivers of climate at seasonal lead times in the extratropics. A mechanistic understanding of these drivers offers insight into where predictability lies in the climate system. Such has been the progress on this topic that skillful seasonal forecasts are now possible (Scaife et al. 2014). Consequently,

Supplemental information related to this paper is available at the Journals Online website: https://doi.org/10.1175/JCLI-D-190423.s1.

Corresponding author: Joe M. Osborne, joe.osborne@metoffice. gov.uk seasonal forecast systems are run operationally by multiple modeling centers around the world.

However, skill in seasonal forecasts in the Northern Hemisphere extratropics is mostly limited to winter. Over the North Atlantic-European (NAE) sector, this largely arises from skillful predictions of the North Atlantic Oscillation (NAO), which is the leading mode of observed winter circulation variability in this region. In winter, several potential sources of skill, or drivers of the NAO, have been identified. These include North Atlantic sea surface temperatures (SSTs) (Rodwell et al. 1999; Scaife et al. 2011; Duchez et al. 2016) acting as a local driver. Other drivers are remote in nature: El Niño-Southern Oscillation (ENSO) (Brönnimann 2007; Bell et al. 2009; Domeisen et al. 2015; Butler et al. 2016); Arctic sea ice cover (Caian et al. 2018), particularly in the Barents-Kara Sea region (Yang and Christensen 
2012); and solar variability (Ineson et al. 2011; Scaife et al. 2013). Many of these drivers have been identified in observations, with subsequent model experiments testing their causality. There is arguably most confidence in ENSO as a driver of the NAO, whereas modeling studies disagree on even the sign of the NAO phase shift in response to reduced Arctic sea ice (Cohen et al. 2014).

Winter appears to offer improved predictability, relative to other seasons (Scaife et al. 2017), because ENSO is usually strongest at this time and the stratospheric polar vortex, which acts as a pathway for Rossby waves, is active (Ayarzagüena et al. 2018). Also, the NAO is a more dominant mode of circulation variability during winter than any other season. Such is the prevalence of winter predictability that forecast skill of the NAO has been shown to "reemerge" during the second winter, 13 months after forecast initialization (Dunstone et al. 2016). Operational seasonal forecast systems generally show negligible skill in summer, although Dunstone et al. (2018) recently highlighted some skill in predicting northern European summer rainfall. This was despite the operational model being unable to accurately simulate interannual variability in the North Atlantic jet stream. Instead, forecast skill was believed to be due to variability in the advection of low-level moisture from the North Atlantic to northern Europe.

Studies looking at summer predictability in the NAE sector typically investigate drivers of variability of the North Atlantic summer jet stream, or storm track, which is often described in the context of the summer North Atlantic Oscillation (SNAO) (Folland et al. 2009). North Atlantic SSTs are also believed to be a driver of the SNAO at different time scales. Recent work using observations has suggested that North Atlantic SSTs that resemble the Atlantic multidecadal oscillation (AMO) can force SNAO-related dynamical responses at interannual time scales (Dong et al. 2013b; O'Reilly et al. 2017). However, the strongest evidence for an influence of North Atlantic SSTs on summer European climate is at the decadal time scale (Sutton and Hodson 2005; Knight et al. 2006; Sutton and Dong 2012), whereby variability of the AMO causes shifts toward wetter or drier regimes, although these studies do not invoke robust dynamical changes behind these shifts. Arctic sea ice variability has been shown to drive shifts in the North Atlantic jet stream and associated circulation patterns in the summer season (Screen et al. 2013; Petrie et al. 2015), although such a source of predictability remains to be identified in seasonal forecast systems.

A focus on just the predictability of the SNAO in generating skillful summer forecasts could be shortsighted, since it explains a smaller proportion of observed circulation variability in the NAE sector relative to its winter counterpart. Additionally, a significant proportion of European summer rainfall variance is determined by poorly understood land-atmosphere interactions, with the soil moisture content at the onset of summer a possible important factor (Schär et al. 1999; Seneviratne et al. 2006, 2010). Indeed, the second dominant mode of observed summer circulation variability is the summer east Atlantic (SEA) pattern, which explains a significant proportion of temperature and precipitation variability over Europe, particularly the United Kingdom (Wulff et al. 2017; Ossó et al. 2018; Neddermann et al. 2019). Observations have been used to show that the SEA pattern is predictable from the previous spring, using an index of local North Atlantic SSTs (Ossó et al. 2018), while Wulff et al. (2017) presented evidence in a modeling study that the SEA pattern is forced by remote ENSO-like tropical SSTs. The forced response in Ossó et al. (2018) is not distinctly SEA-like, however, and appears to also represent the SNAO, which may explain why they did not find tropical forcing and Wulff et al. (2017) did. Gastineau and Frankignoul (2015) used observations and a reanalysis to show that the lagged NAE summer atmospheric response to spring North Atlantic SST variability is SEA-like, with contributions from both tropical and extratropical SSTs. Given that skillful prediction of slowly varying SSTs is possible, especially in the tropics (Barnston et al. 2019), these studies provide optimism that NAE sector atmospheric predictability can be achieved for the summer season also (Palmer and Anderson 1994).

However, significant obstacles remain. Remote forcing from the tropics, whereby tropical rainfall anomalies (due to tropical SST anomalies) induce Rossby wave propagation from the tropics to the extratropics, is a recognized winter process (Hoskins and Karoly 1981; Scaife et al. 2017). Such tropical forcing is hindered in the summer since Rossby waves only propagate in westerly winds (Hoskins and Ambrizzi 1993) and tropical easterlies extend northward with the poleward advancement of the Hadley cell during boreal summer. This is yet another reason why summer predictability is poor. Nevertheless, there is evidence from reanalyses of tropical to extratropical teleconnections in summer (Ding et al. 2011), particularly when the climatological easterly winds over the tropics reverse (Thomson and Vallis 2018). The modeling study of Wulff et al. (2017) was also broadly supported by Thomson and Vallis (2018), who showed that a model of intermediate complexity can simulate similar teleconnections. The exact mechanisms behind these tropical to extratropical teleconnections are not well understood. Likewise, the extratropical atmospheric response to local SSTs is poorly understood with varying, and often contradictory, results across the literature. There is arguably stronger evidence for atmospheric forcing of SSTs in the extratropics with the mixed layer 
ocean temperature response to radiative and turbulent heat fluxes, and wind stress well understood (Dong et al. 2013b; Ossó et al. 2018). Evidence of a response to local SSTs in summer (and winter) is less robust and is mostly based on observational evidence (Dong et al. 2013b; Ossó et al. 2018; Gastineau and Frankignoul 2015; McKinnon et al. 2016). Model experiments give inconsistent responses (Hodson et al. 2010; Dong et al. 2013a), with varying model resolution likely to be behind this lack of consistency since the resolution is key to resolving the strong SST gradients found in the midlatitudes (Minobe et al. 2008; Woollings et al. 2010).

Here, we investigate the role of concurrent North Atlantic SSTs in driving summer atmospheric circulation changes in the NAE sector. We are primarily interested in drivers of circulation variability at interannual time scales since these are most relevant to seasonal prediction. A number of experiments using an atmospheric general circulation model (AGCM) are designed in such a way that we can systematically infer the atmospheric responses to tropical and extratropical SSTs. This approach of isolating the competing influences of different North Atlantic domains is not possible using observations.

Section 2 a uses observations and a reanalysis to show how NAE summer atmospheric circulation varies with North Atlantic (and global) SSTs. It does not separate atmospheric forcing of SSTs from the atmospheric response to SSTs but determines the SST anomalies that are used in the experimental design, which is then discussed in section 2 b. Section 3 looks at the performance of the model in simulating NAE atmospheric and surface variability. Model results are presented in section 4, first considering all responses (section $4 \mathrm{a}$ ), before analyzing in greater detail the response to extratropical North Atlantic SSTs (section 4b) and the response to tropical North Atlantic SSTs (section 4c). Sections 5 and 6 are the discussion and conclusions, respectively.

\section{Methodology and experimental design}

\section{a. Observed SST-atmosphere relationship}

Using mean sea level pressure (MSLP) from the National Centers for Environmental Prediction-National Center for Atmospheric Research (NCEP-NCAR) reanalysis (Kalnay et al. 1996), we calculated the first and second empirical orthogonal functions (EOFs) for summer (June-August) mean MSLP anomalies, for the period 1948-2016 over the NAE sector $\left(25^{\circ}-70^{\circ} \mathrm{N}, 70^{\circ} \mathrm{W}-30^{\circ} \mathrm{E}\right)$. Anomalies were detrended before the calculation of EOFs. The two dominant modes of variability (EOFs) in summer mean MSLP are the SNAO and the SEA pattern (Figs. 1a,b), explaining 36.4\% and $16.2 \%$ of the total variance, respectively. These modes are statistically independent (well separated), according to the test of North et al. (1982), with errors of $36.4 \% \pm 6.2 \%$ and $16.2 \% \pm 2.8 \%$ for EOF1 and EOF2, respectively. Figures $1 \mathrm{a}$ and $1 \mathrm{~b}$ show the positive modes of the SNAO and SEA pattern, as defined by Folland et al. (2009) and Barnston and Livezey (1987), respectively. The SNAO is associated with high pressure anomalies centered over the United Kingdom and northwestern Europe with low pressure anomalies over Greenland, while the SEA pattern is dominated by low pressure anomalies between the United Kingdom and Iceland with weak high pressure anomalies southeast of Newfoundland, Canada.

The relationship between the principal components (PCs) corresponding to the EOFs (see Fig. S1 in the online supplemental material) and summer mean precipitation (detrended anomalies) variability varies spatially but is strongest across northern Europe, especially for the SNAO (Figs. 1c,d). The SNAO is strongly correlated with precipitation over the United Kingdom, with dry conditions during the positive phase (SNAO+). A shift to the negative phase (SNAO-) saw a run of wet summers across the United Kingdom between 2007 and 2012 (Fig. S1) (Dong et al. 2013a; Screen 2013). For the SEA pattern, the relationship with summer mean precipitation is only significant for western regions of the United Kingdom and Ireland, and Scandinavia, probably owing to the maritime nature of its low pressure anomalies. This EOF analysis is not particularly sensitive to the exact time period, variations in the domain bounds and the choice of reanalysis dataset. Repeating the EOF analysis for summer mean $500 \mathrm{hPa}$ geopotential height anomalies (also taken from the NCEP-NCAR reanalysis) gives near identical results for the SNAO (Fig. S2), but the SEA pattern has a region of positive height anomalies centered on the Baltic Sea, which is associated with drierthan-average conditions for nearby land areas, consistent with the study of Wulff et al. (2017). Otherwise, the patterns of the SNAO and the SEA pattern are similar whether defined at the surface or in the midtroposphere.

Folland et al. (2009) found that the SNAO explained $28.3 \%$ of the July-August mean MSLP variance over a similar domain $\left(25^{\circ}-70^{\circ} \mathrm{N}, 70^{\circ} \mathrm{W}-50^{\circ} \mathrm{E}\right)$. Repeating the EOF analysis for winter (December-February) mean MSLP anomalies the winter North Atlantic Oscillation explains $45.1 \%$ of the variance, compared to $36.4 \%$ for the summer. This further highlights the importance of the NAO in NAE summer climate, as well as winter, and suggests that predictability of the SNAO could well be key to generating skillful summer forecasts. We therefore consider SSTs related to the SNAO to investigate the extent to which this relationship can be attributed to an atmospheric response to SSTs through a number of AGCM experiments. If the SNAO pattern is at least 
a)

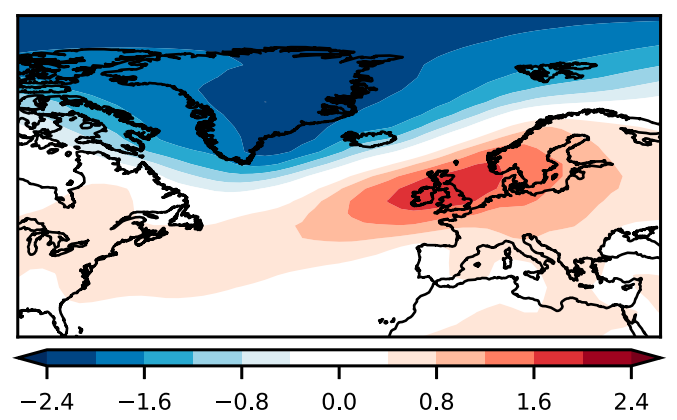

c) Precipitation $\left(\mathrm{mm} \mathrm{day}^{-1}\right)$; EOF1

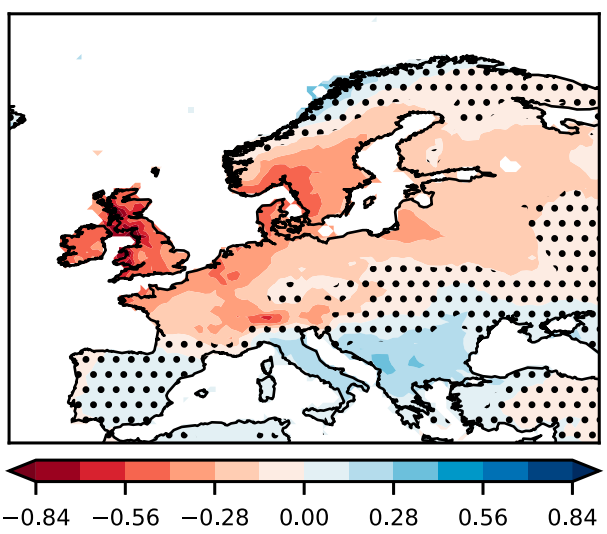

b)

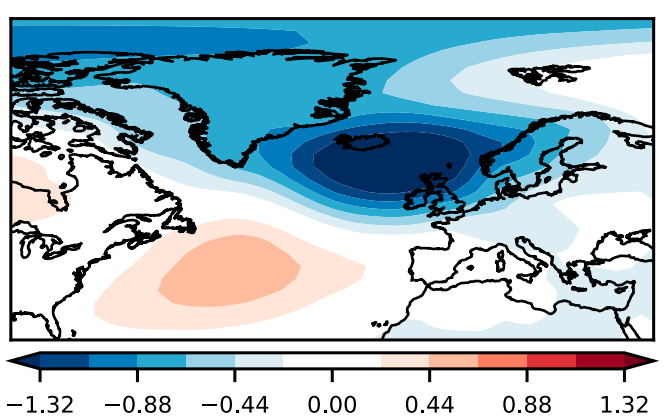

d) Precipitation $\left(\mathrm{mm} \mathrm{day}^{-1}\right)$; EOF2

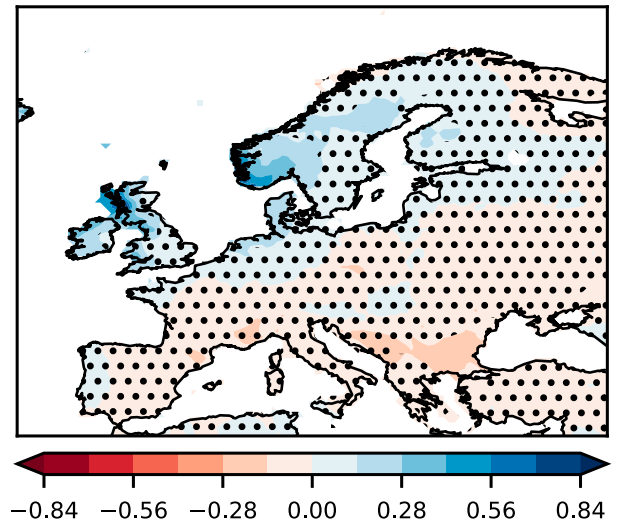

FIG. 1. (a) EOF1 (SNAO) of summer mean MSLP for the period 1948-2016 over the NAE sector and (b) EOF2 (SEA pattern). (c),(d) Regressions of CRU TS4.02 summer mean precipitation on the corresponding PCs of EOF1 and EOF2, respectively (units are per standard deviation of the PC time series). Percentages of total variance explained by the EOFs are given in the titles of (a) and (b). Stippling in (c) and (d) shows where regressions are not statistically significant at the $95 \%(p=0.05)$ confidence level based on a two-tailed $t$ test.

partly forced by these SSTs, then we might expect to see a SNAO-like response in our simulations. This relies on a realistic representation of NAE summer circulation variability and assumes that the true response is not hidden by biases in the model. The null hypothesis is that these SSTs do not lead to a robust response, SNAO-like or otherwise, implying a strong role for atmospheric forcing of SSTs (Branstator and Selten 2009).

Figure 2 shows the linear regression patterns of observed March-August, and spring (March-May) mean and summer mean SST on the observed SNAO index, for 19482016. Observed SSTs were taken from the Met Office Hadley Centre Sea Ice and Sea Surface Temperature dataset (HadISST) (Rayner et al. 2003) and detrended, while the observed SNAO index was taken as the PC corresponding to EOF1 (the SNAO) (Fig. S1). The precursor spring SST anomalies consist of an AMO-like horseshoe shape (Alexander et al. 2014), with negative anomalies extending from the subpolar gyre, to western Europe and spanning much of the tropical/subtropical North Atlantic (Fig. 2). Concurrent summer SST anomalies differ in that they show a tripole structure across the North Atlantic, which develops strongly in July. There is cooling and an increase in the magnitude of SST anomalies in the subpolar gyre, but a warming across an extratropical band extending from Newfoundland, Canada, to the United Kingdom. This warming is such that SST anomalies around the United Kingdom change sign from negative SST anomalies to positive SST anomalies. Anomalies in the tropical/subtropical North Atlantic remain largely unchanged. Dong et al. (2013b) showed that this spring to summer transition in SST anomalies can be accounted for by the ocean mixed layer response to atmospheric circulation anomalies in summer but suggested a role for a feedback from the ocean in forcing atmospheric anomalies. Outside of the North Atlantic the SST anomalies related to the SNAO are generally weak and do not show signatures relating to natural climate variability, such as ENSO.

The summer tripole structure in Fig. 2 is a result of the high-frequency, interannual variability of the SNAO. Removing the low-frequency variability, using a $10-y r$ 
a)

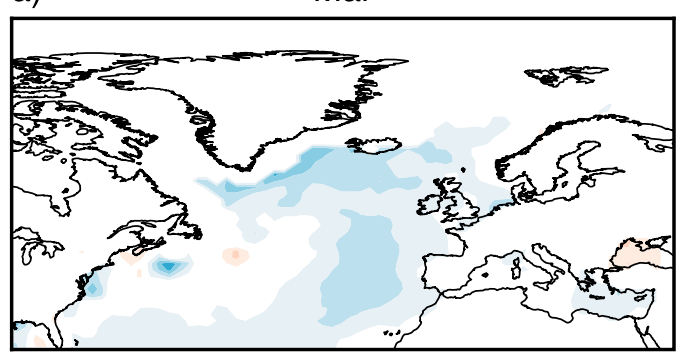

c)

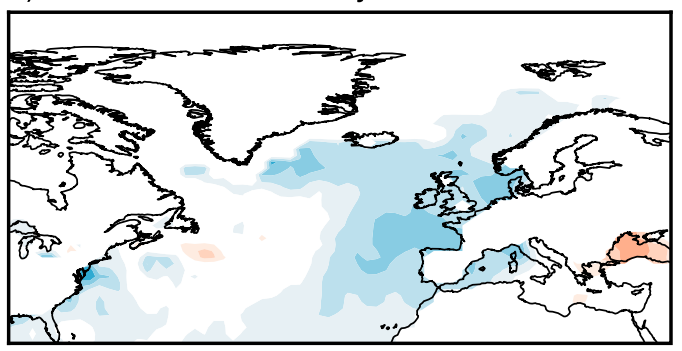

e)

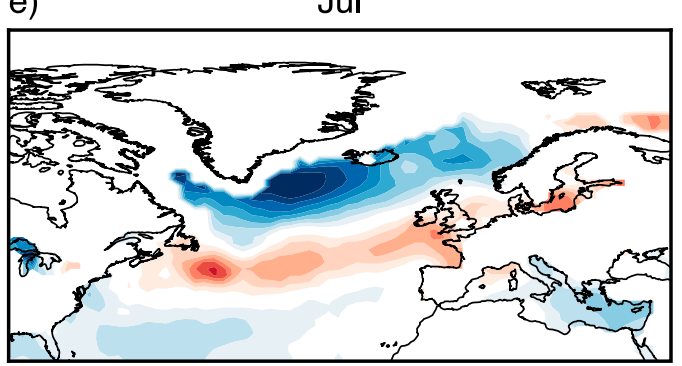

g)

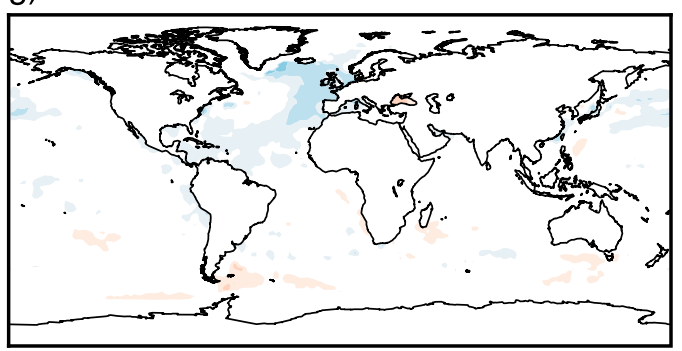

b)

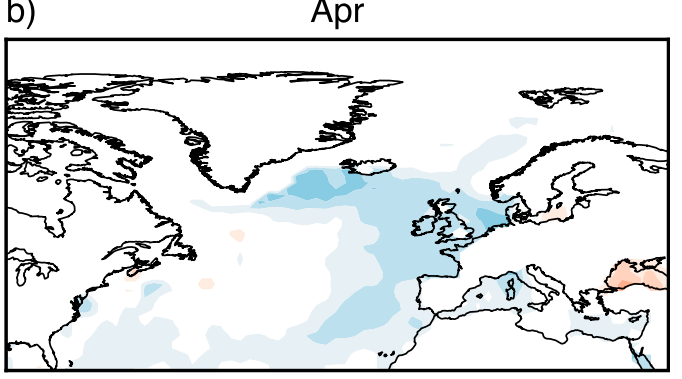

d)

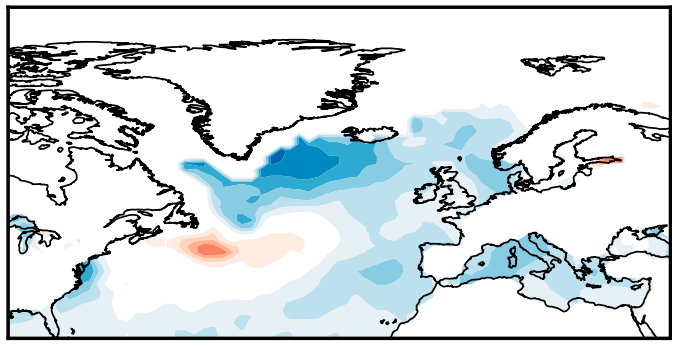

f)

Aug

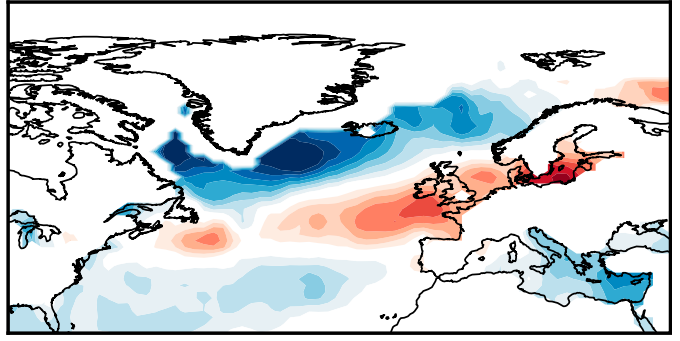

h)

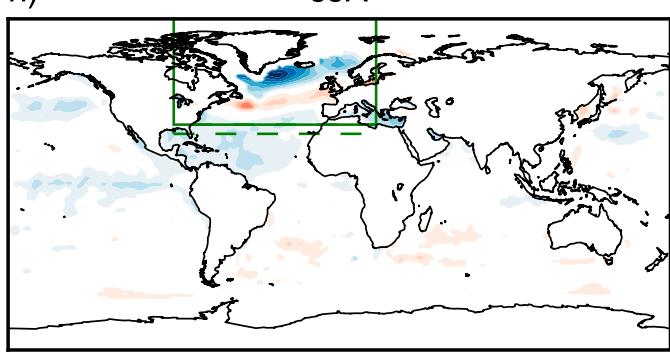

$-0.72$

$-0.36$

0.00

0.36

0.72

${ }^{\circ} \mathrm{C}$

FIG. 2. Linear regression patterns of observed (a)-(f) March-August, (g) MAM mean, and (h) JJA mean SST on the observed SNAO index multiplied by 2 (representing the prescribed SST anomalies in the GLO-COLD experiment). The green box in (h) shows the domain over which SST anomalies are prescribed in the ATL-COLD and ATL-WARM experiments $\left(32.5^{\circ}-90^{\circ} \mathrm{N}, 90^{\circ} \mathrm{W}-20^{\circ} \mathrm{E}\right)$, with the area bounded by dashed lines representing where SSTs are linearly smoothed southward to the climatology $\left(27.5^{\circ}-32.5^{\circ} \mathrm{N}\right)$.

low-pass filter (Fig. S3), and regressing observed SST on the high-frequency, or interannual, component of the SNAO index results in almost identical summer SST anomalies (Fig. S4). There is some sensitivity to this step in the spring SST anomalies, suggesting a large part of the AMO-like signature in Fig. 2 is due to low-frequency variability. Since only the summer response is considered here, any robust circulation response is expected to 

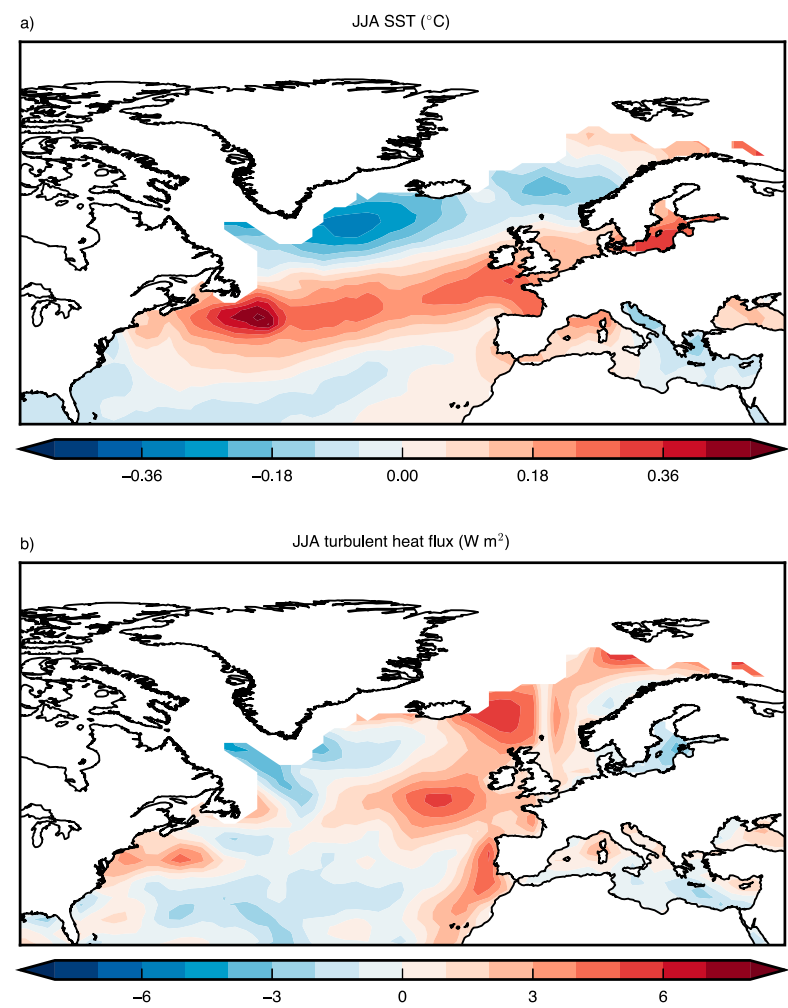

FIG. 3. Linear regression patterns of (a) observed JJA mean SST and (b) observed JJA mean turbulent heat flux on the highfrequency component of the observed SNAO index. The sign for turbulent heat flux is defined as positive downward (from the atmosphere to the ocean).

be due to SST anomalies related to the interannual variability of the SNAO. Further evidence for atmospheric forcing of SSTs in the extratropics can be found by investigating the relationship between surface turbulent heat flux and the SNAO, and, in turn, SST anomalies (Fig. 3). The sign for turbulent heat flux is defined as positive downward (from the atmosphere to the ocean). Following Gulev et al. (2013), we retain just the interannual component of variability. The regression of observed summer mean turbulent heat flux (also taken from the NCEP-NCAR reanalysis) on the observed SNAO index reveals that the turbulent heat flux anomalies are broadly collocated with the tripole pattern in the SST anomalies. Positive and negative turbulent heat flux anomalies are related to positive and negative SST anomalies, respectively. This was found to be the case for the winter North Atlantic Oscillation (Deser et al. 2010), although turbulent heat flux anomalies are significantly smaller in the summer, due to weaker winds and a smaller difference between sea surface and air temperatures. There are a few exceptions, with the positive correlation not as evident in the western part of the extratropical band, close to Newfoundland, Canada, and evidence for a negative correlation north of the United Kingdom, perhaps suggesting a role for anomalous Ekman transports or radiative fluxes here. Regardless, turbulent heat flux anomalies related to the SNAO appear to play a role in determining structure of the SST anomaly tripole, particularly where the SST gradients are strongest in the western North Atlantic. In keeping with the findings of Gulev et al. (2013), this suggests that the surface turbulent heat fluxes are driven by the atmosphere (the SNAO), which in turn force the North Atlantic Ocean.

\section{b. Experimental design}

These linear regression patterns were used for prescribing SST boundary conditions for a series of AGCM experiments. The atmospheric component (HadGEM3A) of the Met Office Hadley Centre general circulation model (GCM) HadGEM3 was used. The model uses the Global Atmosphere 7.0 configuration and Unified Model, version 10.5 (Walters et al. 2017), and was run at N96 horizontal resolution $\left(1.875^{\circ} \times 1.25^{\circ}\right.$ in longitude and latitude, respectively) with 85 vertical levels. While the AGCM was forced with prescribed SSTs and sea ice concentrations (SICs), greenhouse gases (GHGs), and other radiatively active species were held constant.

A total of five experiments were performed. A control experiment (CTL) was forced with annually repeating monthly cycles of climatological SST $\left(\mu_{\mathrm{SST}}\right)$ and SIC, averaged over the period from September 1947 to August 2016. SIC and SST data are from HadISST (Rayner et al. 2003). Two experiments were prescribed with SSTs related to SNAO+ and SNAO-. For each calendar month and in grid boxes that are always ice free we applied an SST anomaly to the climatological SST. The SST anomaly was calculated by regressing observed and detrended SST on the observed SNAO index (taken as PC1; 1948-2016) for each precursor/concurrent calendar month, from September to August (using SSTs from September 1947 to August 2016). This gives an SST anomaly per standard deviation departure in the SNAO index $\left(\beta_{\mathrm{SST}}\right)$. We prescribed SST anomalies of $\mu_{\mathrm{SST}}+$ $2 \beta_{\mathrm{SST}}$ and $\mu_{\mathrm{SST}}-2 \beta_{\mathrm{SST}}$ for the two experiments relating to $\mathrm{SNAO}+$ and SNAO-, respectively. The anomalies were multiplied by two in an attempt to counteract an expected small signal-to-noise ratio, which is typical in studies investigating the atmospheric response to extratropical SST anomalies (Kushnir et al. 2002). However, prescribed SSTs are within the extremes of what has been observed so that the results are relevant to the real climate system. In these two experiments, the SSTs were prescribed globally and are referred to as GLO-COLD and GLO-WARM for SNAO+ and SNAO-, respectively. COLD and WARM refer to the dominant SST 
anomalies in the North Atlantic basin in the precursor/ concurrent months of the respective SNAO phases.

Two further experiments were prescribed with SSTs related to SNAO+ and SNAO - over the extratropical North Atlantic only $\left(32.5^{\circ}-90^{\circ} \mathrm{N}, 90^{\circ} \mathrm{W}-20^{\circ} \mathrm{E}\right)$. SSTs were linearly smoothed southward to the climatology at $27.5^{\circ} \mathrm{N}$ over the longitude range of the extratropical North Atlantic domain. Elsewhere, climatological SSTs were prescribed. These experiments are referred to as ATL-COLD and ATL-WARM for $\mathrm{SNAO}+$ and $\mathrm{SNAO}-$, respectively. Over the extratropical North Atlantic SSTs are identical in the GLOCOLD and ATL-COLD experiments, and identical in the GLO-WARM and ATL-WARM experiments. The SST anomalies are shown in Fig. 2. These represent GLOCOLD, but the GLO-WARM anomalies are simply the mirror image of these. Figure $2 \mathrm{~h}$ shows the domain over which SST anomalies were prescribed in the ATL-COLD and ATL-WARM experiments.

In a further effort to increase the signal to noise, each of the five experiments was run for 125 years. Each year was initialized from the atmospheric state at the end of the previous year and as such is treated as independent, or a separate ensemble member. The atmospheric response to SSTs related to the SNAO is calculated as the difference between the ensemble means of the GLO-COLD and GLO-WARM experiments or the ATL-COLD and ATL-WARM experiments. Note that the use of response hereinafter relates to the difference between two forced experiments, rather than the difference between a forced experiment and the control experiment, except where otherwise stated. This is again motivated by the expectation that this will increase the signal to noise. The significance of the ensemble mean difference is computed using a Student's $t$ test, with the null hypothesis of equal means rejected with $95 \%$ confidence when $p \leq 0.05$. Since extratropical North Atlantic SSTs are identical in the GLO-COLD and ATL-COLD experiments, the difference between the ensemble means of these two experiments is equivalent to the atmospheric response to SSTs related to the SNAO but outside of this domain. The region with significant SST anomalies outside of this domain and perhaps capable of forcing an extratropical atmospheric response is the tropical North Atlantic (Fig. 2). We therefore refer to the difference in means as TRO-COLD, with the difference between the ensemble means of the GLO-WARM and ATL-WARM experiments being TRO-WARM. This approach assumes linearity in the atmospheric responses to extratropical SSTs and tropical SSTs. Where nonlinear processes are important this assumption could be violated.

\section{Model performance}

We first evaluate the capability of the model to simulate realistic modes of variability. Considering the CTL experiment, the leading mode of variability (EOF1) in summer mean MSLP is the SEA pattern, explaining $26.7 \%$ of the total variance, while EOF2 corresponds to the SNAO, explaining $21.1 \%$ of the total variance (Figs. 4a,b). These modes are reasonably distinct from each other, according to the test of North et al. (1982), with errors of $26.7 \% \pm 3.4 \%$ and $21.1 \% \pm 2.7 \%$ for EOF1 and EOF2, respectively. They are not entirely distinct, although we have confidence in these being the robust leading modes in the model given our a priori expectation from the observed EOFs, and the fact that the EOF analysis is not particularly sensitive to the exact time period or variations in the domain bounds. Similar results are returned when considering all five experiments collectively, with values of $25.2 \%$ and $21.7 \%$ for the SEA pattern and the SNAO, respectively. Folland et al. (2009) reported similar results in an earlier version (HadGEM1) of the model, run coupled to the ocean, with explained variances of $26.8 \%$ and $18.0 \%$ for the SEA pattern and the SNAO, respectively. A study by Bladé et al. (2012) found that EOF2 most resembled the SNAO in 6 out of 24 CMIP 3 models, suggesting that this is not unique to HadGEM1, although also not commonplace. Further, the HadGEM2 (Collins et al. 2011) 576-yr preindustrial control contribution to the CMIP5 dataset also simulates the SEA pattern as EOF1 (explained variances of $28.3 \%$ and $17.1 \%$ for the SEA pattern and the SNAO, respectively; not shown). This indicates that this behavior is inherent to several generations of Met Office Hadley Centre models.

Conversely, EOF1 of summer mean $500 \mathrm{hPa}$ geopotential height is the SNAO, although with the node of low pressure anomalies close to Greenland positioned farther south (Figs. 4c,d). The spatial correlation with the observed SNAO is 0.71 (cf. Fig. $4 \mathrm{c}$ and Fig. S2a), far stronger than the correlation with any of the leading 10 EOFs (not shown). EOF2 corresponds to the SEA pattern. Explained variances are $24.3 \%$ and $19.9 \%$, respectively. The order of the EOFs is the same as seen in the NCEP-NCAR reanalysis, although the SNAO is clearly the dominant mode of variability in the reanalysis (cf. Figs. 4c,d and Figs. S2a,b). Although we do not further investigate the consistency of the overly dominant SEA pattern across the various generations and configurations, or indeed the models of other climate modeling groups, the implications of this will be considered when interpreting the results.

\section{Model results}

\section{a. Atmospheric response}

Figure 5 shows the response of surface variables to SSTs in the various experiments. Positive and significant 

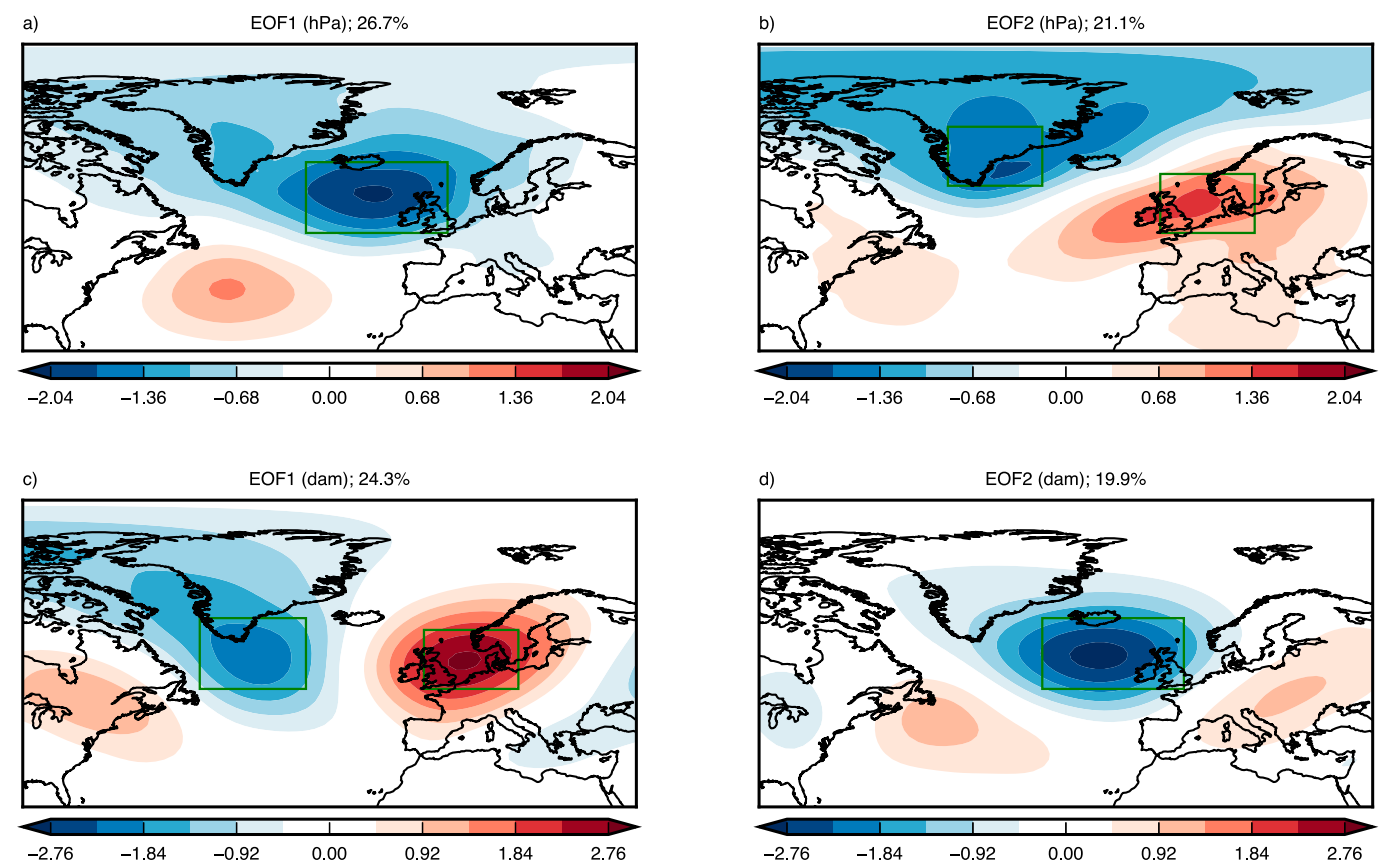

FIG. 4. (a) EOF1 (SEA pattern) of summer mean MSLP in the 125-yr CTL experiment and (b) EOF2 (SNAO). (c) EOF1 (SNAO) of summer mean $500 \mathrm{hPa}$ geopotential height in the 125-yr CTL experiment and (d) EOF2 (SEA pattern) The green boxes represent the nodes over which the modes of variability are calculated (see text).

MSLP anomalies are seen over much of the NAE sector in response to GLO SSTs (Fig. 5a). This appears to be dominated by the response to SSTs outside of the extratropical North Atlantic (TRO SSTs), with what is likely to be a local response in the western subtropical North Atlantic, as well as a remote response centered west of the United Kingdom (Fig. 5c). The response to extratropical North Atlantic SSTs (ATL SSTs) is weaker, although there are significant cyclonic MSLP anomalies southwest of the United Kingdom and significant anticyclonic anomalies west of Iceland (Fig. 5b). This has the appearance of a SNAO- response at the surface, although the robustness of this is considered in more detail later. Generally, there are larger magnitude anomalies in response to TRO SSTs than ATL SSTs. Near-surface zonal wind responses reflect the changes in surface circulation (Figs. $5 \mathrm{~d}-\mathrm{f}$ ). There is a significant decrease in precipitation over the western tropicalto-subtropical North Atlantic, representing a local response to negative SST anomalies in this region in TRO-COLD TRO-WARM (Fig. 5i). This significant response is also apparent in the response to GLO SSTs (Fig. 5g). The extratropical precipitation response to GLO SSTs is limited to a region of negative precipitation anomalies near Iceland, although this disguises significant positive and negative anomalies around the United Kingdom in response to ATL SSTs and TRO SSTs, respectively (Figs. 5h,i), which cancel in the combined GLO SSTs response.
There are also significant atmospheric circulation responses at higher altitudes (Fig. 6). There is a decrease in $500 \mathrm{hPa}$ geopotential height across much of the tropicalto-subtropical North Atlantic in response to GLO SST, with TRO SSTs dominant in forcing this response (Figs. 6a,c). These cyclonic circulation anomalies in the midtroposphere contrast to the anticyclonic anomalies at the surface. In response to TRO SSTs there remains an anomalous anticyclonic circulation centered just to the west of the United Kingdom (cf. Figs. 5c and 6c), albeit not significant at this pressure level. This has the appearance of a negative SEA pattern (SEA-) response. Conversely, the response to ATL SSTs is dominated by a significant decrease in $500 \mathrm{hPa}$ geopotential height, centered over the same region, representative of a positive SEA pattern (SEA+) response (Fig. 6b), explaining why there is no significant response here in the combined GLO SSTs case. There are also cyclonic anomalies across much of the high-latitude region of the NAE sector in response to GLO SSTs, again a consequence of a response to SSTs outside of the extratropical North Atlantic (Figs. 6a,c), highlighting the ability of these SSTs to force remote responses. The most apparent $300 \mathrm{hPa}$ zonal wind response is in the TRO SSTs case, with positive and significant westerly wind anomalies between the United Kingdom and Iceland and negative westerly wind anomalies southwest of the 

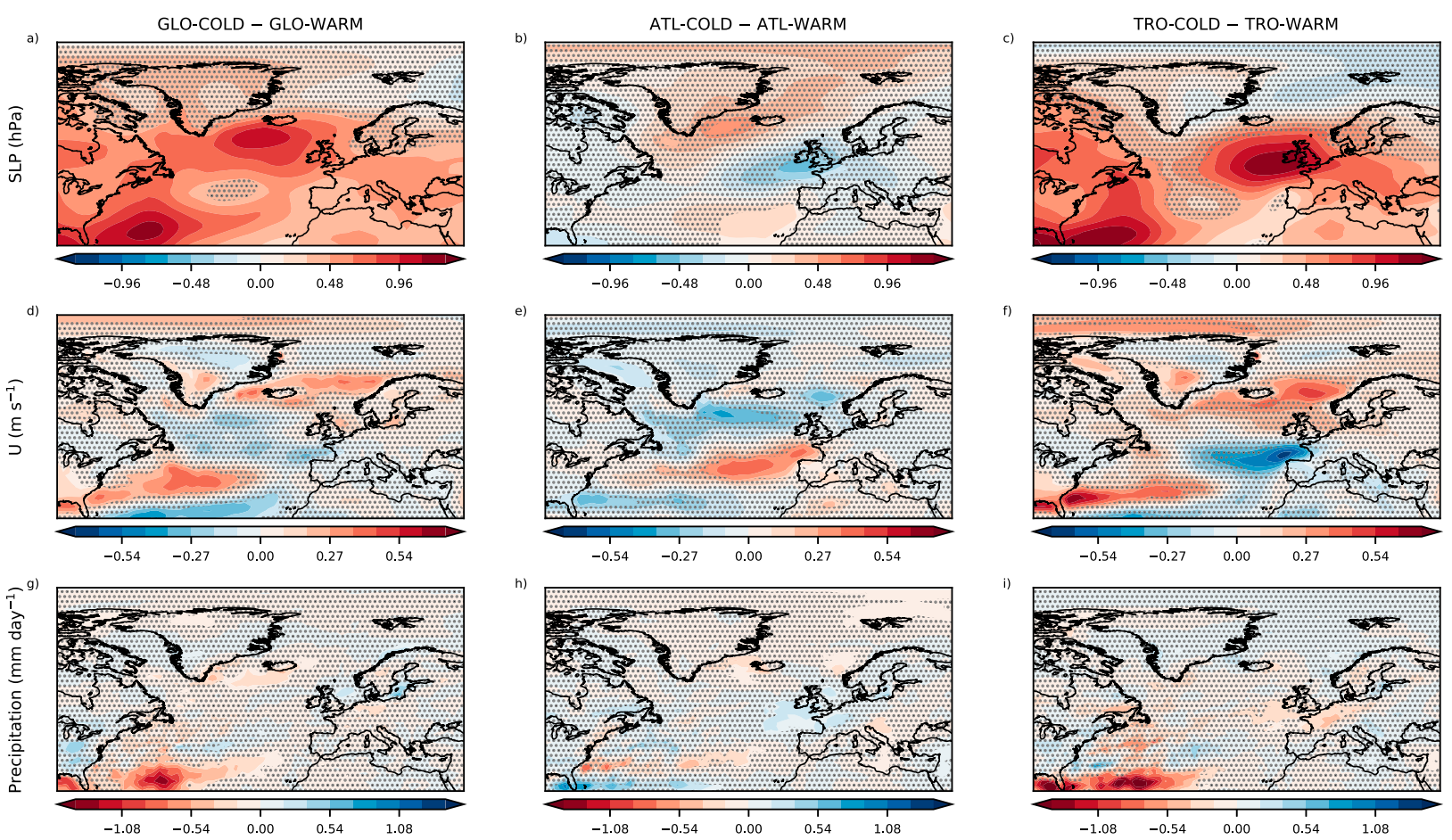

FIG. 5. (a)-(c) Summer MSLP, (d)-(f) near-surface zonal wind, and (g)-(i) precipitation responses to (left) GLO SSTs (GLO-COLD GLO-WARM), (center) ATL SSTs (ATL-COLD - ATL-WARM), and (right) TRO SSTs (TRO-COLD - TRO-WARM). Stippling shows where responses are not statistically significant at the $95 \%(p=0.05)$ confidence level based on a two-tailed $t$ test.

United Kingdom, indicative of a poleward shift in the North Atlantic eddy-driven jet, which is related to the SEA - pattern (Fig. 6f). The opposite pattern is apparent in relation to the SEA+ pattern in response to ATL SSTs but is weaker and confined to a small region (Fig. 6e) and, as such, the response to TRO SSTs dominated the response to GLO SSTs (Fig. 6d). There is a pattern of alternating $300 \mathrm{hPa}$ meridional wind responses in the TRO SSTs case (Fig. 6i) suggestive of a dynamical response (wave propagation) from tropical SST anomalies.

We further investigate the projection of these responses onto the SNAO and SEA pattern. Using the information from section 3, we determine the nodes (represented by the green boxes in Fig. 4) over which to calculate indices for the modes of variability. For the SNAO defined using MSLP we take the difference between the boxes located over the North Sea $\left(50^{\circ}-62.5^{\circ} \mathrm{N}, 5^{\circ} \mathrm{W}-15^{\circ} \mathrm{E}\right)$ and Greenland $\left(60^{\circ}-72.5^{\circ} \mathrm{N}, 50^{\circ}-30^{\circ} \mathrm{W}\right)$. When defining the SNAO index using $500 \mathrm{hPa}$ geopotential height the slight shift in the Greenland node is accounted for by using a more southerly box: $50^{\circ}-65^{\circ} \mathrm{N}, 52.5^{\circ}-30^{\circ} \mathrm{W}$. The SEA pattern is calculated over a box centered between the United Kingdom and Iceland: $50^{\circ}-65^{\circ} \mathrm{N}, 30^{\circ} \mathrm{W}-0^{\circ}$. We calculated $125-\mathrm{yr}$ indices for all five experiments as well as the two derived TRO SSTs experiments. A significant SEA pattern is seen at the surface in response to TRO SSTs, which is also apparent in response to GLO SSTs (Figs. 7g,i). The responses in TROCOLD and TRO-WARM appear symmetrical about the CTL experiment (Fig. 7i). Using $500 \mathrm{hPa}$ geopotential height, there is a significant SEA pattern response to ATL SSTs, although this is asymmetrical about the CTL experiment and mostly due to an SEA - pattern response in ATL-WARM (recall that SEA+ is defined as a decrease in $\mathrm{MSLP} / 500 \mathrm{hPa}$ geopotential height, or a cyclonic circulation) (Fig. 7k).

There is also some evidence for robust and opposite SNAO responses to ATL SSTs and TRO SSTs at the surface (Figs. 7b,c), with the $p$ values of the difference in means less than 0.1 in each case. However, we question the robustness of these responses. Arbitrarily, roughly halving the ensemble size and taking the first 70 years of the simulation produces similar results for the responses that were significant at the $95 \%$ confidence level in the full ensemble, but noticeably different (and no longer significant) results for these two that are marginal (Fig. S5). The apparent SNAO+ response to TRO SSTs is little more than an SEA - response that also spans the southerly node of the SNAO (Fig. 5c). While we have reason to question the robustness of the SNAO- response to ATL SSTs, it is also pertinent to highlight that it is limited to a surface response and even low-level tropospheric responses (e.g., 850 and $700 \mathrm{hPa}$ ) appear as 

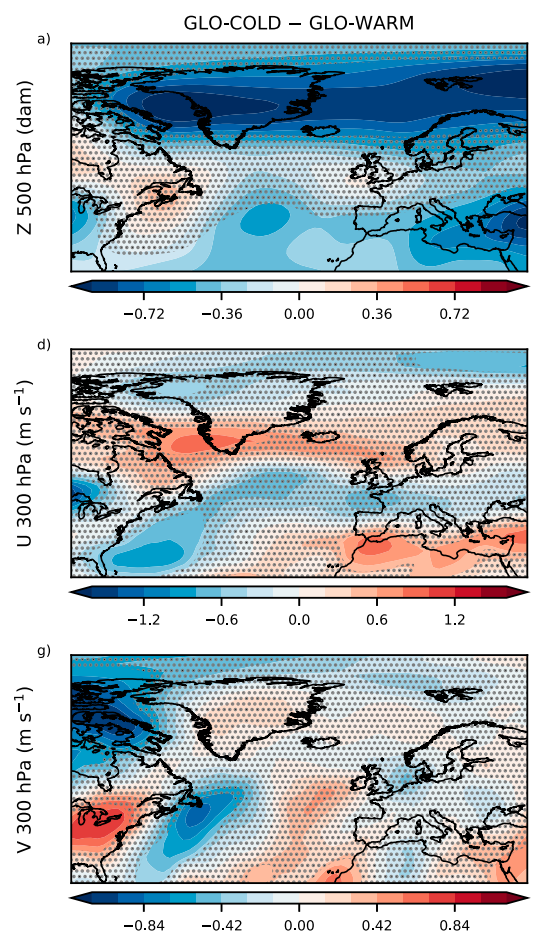
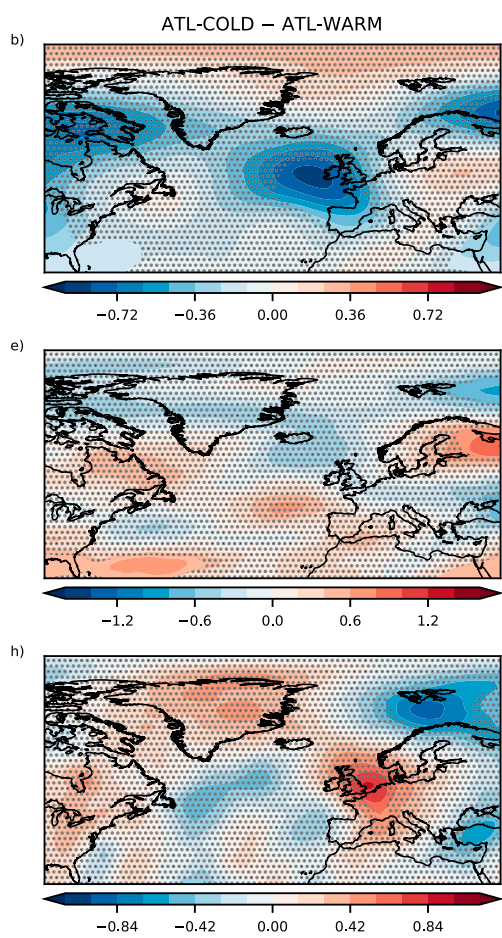

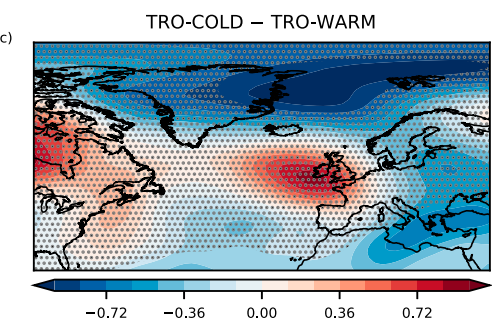

f)

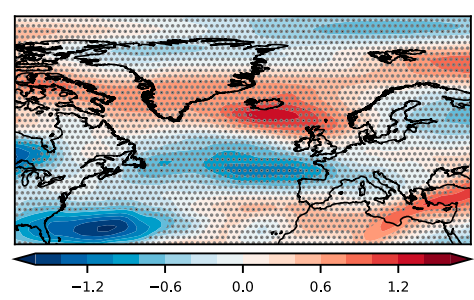

i)

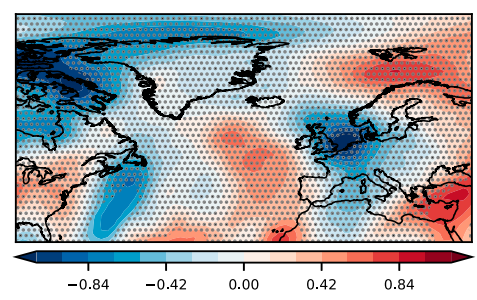

FIG. 6. As in Fig. 5, but for (a)-(c) summer $500 \mathrm{hPa}$ geopotential height, (d)-(f) $300 \mathrm{hPa}$ zonal wind responses, and (g)-(i) $300 \mathrm{hPa}$ meridional wind responses.

the SEA - pattern. Therefore, we interpret the robust response to ATL SSTs as SEA-like and most obvious in the midtroposphere.

\section{b. The response to extratropical North Atlantic SSTs}

Confident that the response to extratropical North Atlantic SSTs (ATL SSTs) projects onto the SEA pattern, we consider why this might be so, given that the prescribed SST boundary conditions are related to the SNAO. Specifically, the prescribed SST anomalies are related to SNAO+ (ATLCOLD - ATL-WARM). The fact that we see a robust extratropical atmospheric response to local SSTs lends support to an ocean influence on the atmosphere here. A key to explaining the SEA pattern response could lie in its overly dominant role in summer circulation variability in the NAE sector, relative to what is observed. We explore the reason behind this in more detail by considering the CTL experiment. Comparing the summer mean climatologies of the CTL experiment and the climatology from the NCEPNCAR reanalysis for the period 1948-2016, it can be seen that the $300 \mathrm{hPa}$ zonal wind (an analog for the eddy-driven jet) is biased to the north and east in the CTL experiment (Fig. 8a). The jet stream maximum in the reanalysis is situated just off the coast of Newfoundland, Canada, whereas it is biased toward the mid-Atlantic in the model. This is consistent with biases in the Eady growth rate $\sigma$, which is calculated as

$$
\sigma=0.31 \frac{f}{N}\left|\frac{d u}{d z}\right|,
$$

where $f$ is the Coriolis parameter, $N$ is the Brunt-Väisälä frequency, $u$ is the zonal wind, and $z$ is the vertical height. The Eady growth rate serves as a measure of baroclinic instability and the jet maximum is generally located close to the region of maximum baroclinicity. At $500 \mathrm{hPa} \sigma$ is also strongly biased to the north and east in the CTL experiment (Fig. 8b). Therefore, the shifted jet is consistent with biases in the maximum of baroclinicity. This also holds when considering the $850 \mathrm{hPa}$ zonal wind and the $850 \mathrm{hPa}$ Eady growth rate (Fig. S6). Analysis at this lower-troposphere level ensures that we fully capture the eddy-driven jet and not also some component of the subtropical jet.

The reason for the bias in maximum baroclinicity could be biases in the lower-troposphere temperature pattern over the extratropical North Atlantic. The summer mean climatology of $850 \mathrm{hPa}$ temperature is biased cold here in the CTL experiment, most notably over the subpolar gyre (Figs. 9a-c). Consequently, the maximum in the lowertroposphere (planetary boundary layer) meridional temperature gradient is biased to the north and east in the CTL experiment (Figs. 9d-f). Therefore, the maximum lowertroposphere meridional temperature gradient is not collocated with the maximum meridional SST gradient in the 
CTL experiment. The bias in this temperature gradient leads to a shift in the peak near-surface baroclinicity, which is key to storm growth and, in turn, anchoring the storm track and jet stream. The strong relationship between the latitude of the maximum in meridional temperature gradient and the latitude of the jet stream has been shown previously (Woollings et al. 2010; Sung et al. 2014) and is also evident here (Fig. S7). The same results are found when considering the temperature at $925 \mathrm{hPa}$ (not shown), suggesting that the temperature pattern biases exist close to the prescribed SST boundary conditions. These biases in the climatology of the jet could explain why variability, whether natural or forced, about its mean state project onto SEA pattern variability. The SEA pattern is associated with meridional variability in the jet about a more northerly dipole (not shown), which is favored in the model due to the biased mean state.

\section{c. The response to tropical North Atlantic SSTs}

The local positive and significant MSLP anomalies in the western subtropical North Atlantic in response to TRO SSTs (Fig. 5c) is consistent with other studies. Dong et al. (2013a) found a similar response (note that they found a cyclonic response to positive SST anomalies, whereas we found an anticyclonic response to negative SST anomalies). This appears to be consistent with a Gill-like response to diabatic heating over this region, in response to SST anomalies, as indicated by the precipitation response (Fig. 5i). This type of response has been documented in previous literature (Hodson et al. 2010; Thomson and Vallis 2018). The anticyclonic MSLP response centered west of the United Kingdom (Fig. 5c) is a remote response since there are no local extratropical SST anomalies in these inferred experiments.

Returning to the prescribed SST anomalies (Fig. 2h), the largest magnitude SST anomalies outside of the extratropical North Atlantic are in the tropical North Atlantic, the equatorial east Pacific and the extratropical North Pacific. Given that the only significant local precipitation anomalies in response to these SST anomalies are in the tropical North Atlantic, particularly the Caribbean region, we suggest that this might be the source of this remote response close to the United Kingdom. Such significant precipitation anomalies could be capable of forcing diabatic heating anomalies that lead to a Rossby wave train propagating out of the tropics. There is strong evidence for this when looking at the $200 \mathrm{hPa}$ velocity potential. There is a positive velocity potential anomaly extending over the tropical North Atlantic and eastern tropical North Pacific in response to GLO SSTs, with TRO SSTs clearly forcing this response (Figs. 10a,c). This is indicative of large-scale ascent in response to warm SST anomalies in the tropical North Atlantic in the inferred TRO-WARM experiment.
Such ascent, and the associated diabatic heating anomalies, indicates a potential Rossby wave source. This is confirmed in Fig. S8, which shows a clear Rossby wave source (Sardeshmukh and Hoskins 1988) anomaly in response to both TRO SSTs and GLO SSTs. Wulff et al. (2017) presented evidence for an SEA response to opposing diabatic heating anomalies in the tropical Pacific and Caribbean. Here, SST anomalies are of the same sign across these regions, making a direct comparison to their results difficult. However, similar mechanisms appear to be operating.

\section{Discussion}

We find that there is an expectedly small signal-tonoise ratio in the local atmospheric response to extratropical North Atlantic SST anomalies (Kushnir et al. 2002). The need for very large ensembles is consistent with previous work and theory (Dunstone et al. 2018). Whether this is entirely due to weak forcing from the extratropical North Atlantic to the local atmosphere, or the prevalence of the "signal-to-noise paradox" that is evident in the response to different drivers in climate models, is hard to tell without a direct comparison to observed variability (Scaife and Smith 2018). Tellingly, this paradox is particularly obvious in the NAE sector (Eade et al. 2014; Dunstone et al. 2016). However, we do find some robust responses. While not robust at the surface, the response to extratropical North Atlantic SST anomalies appears to robustly project onto the SEA pattern, the second dominant mode of summer atmospheric circulation variability, at altitude. At the surface, there appears to be a larger and more robust extratropical response to smaller magnitude SST anomalies in the tropical North Atlantic, than to larger magnitude local SST anomalies. This also projects onto the SEA pattern, but the opposite phase to the extratropical case for the same sign of SST anomalies. This response is still evident but does not appear to be as robust at altitude (500 hPa; Fig. 6). Such a remote influence appears to be due to the propagation of Rossby waves, due to SST anomalies and associated precipitation and diabatic heating anomalies. Such propagation is hindered in the summer months due to the extent of easterlies across the Northern Hemisphere tropics, yet there is a growing body of recent work indicating the importance of such mechanisms in forcing extratropical summer circulation anomalies (Ding et al. 2011; Gastineau and Frankignoul 2015; Wulff et al. 2017; Thomson and Vallis 2018).

It should be noted that a limitation of our approach is that it relies on the linearity of atmospheric responses to extratropical and tropical SSTs, since we derive the tropical experiments (TRO-WARM and TRO-COLD) from the other experiments. There are likely to be some 
GLO

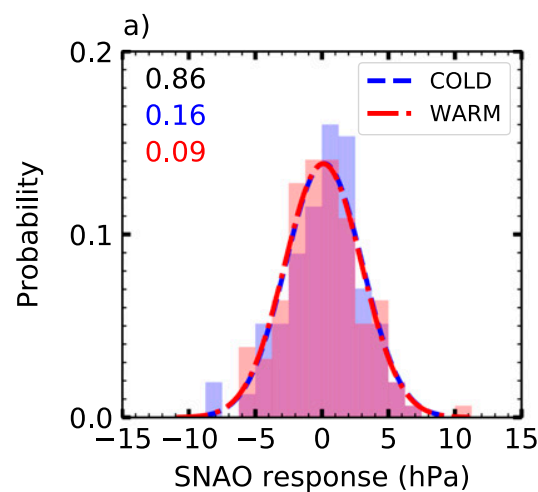

d)
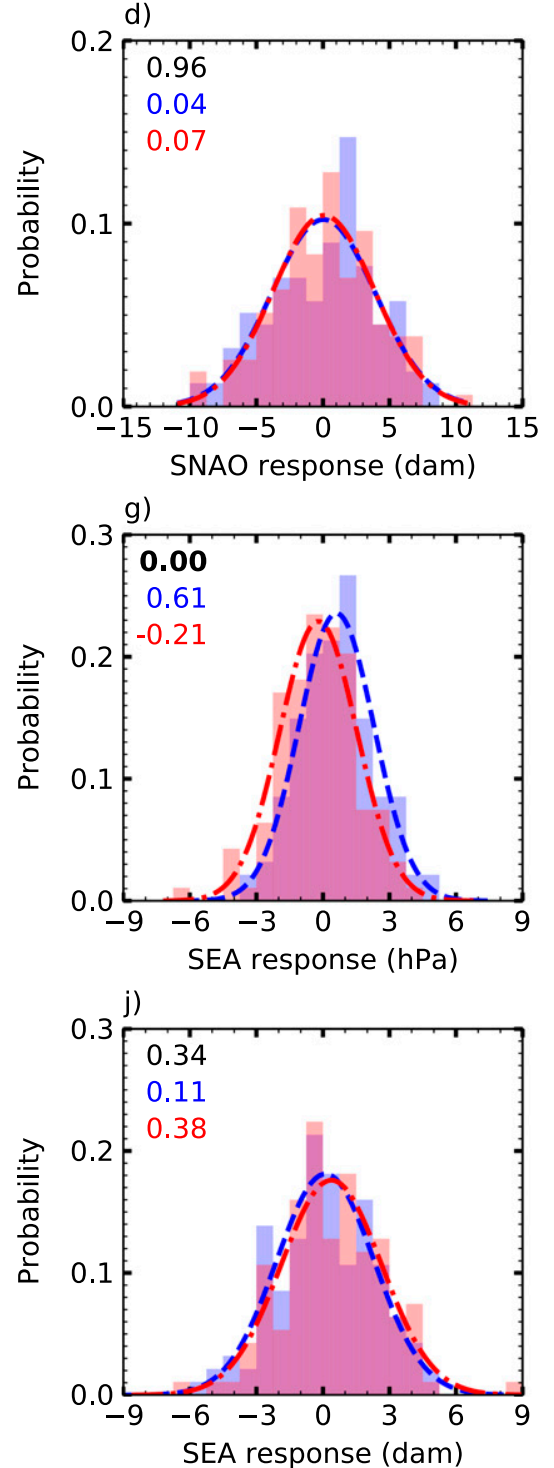

ATL
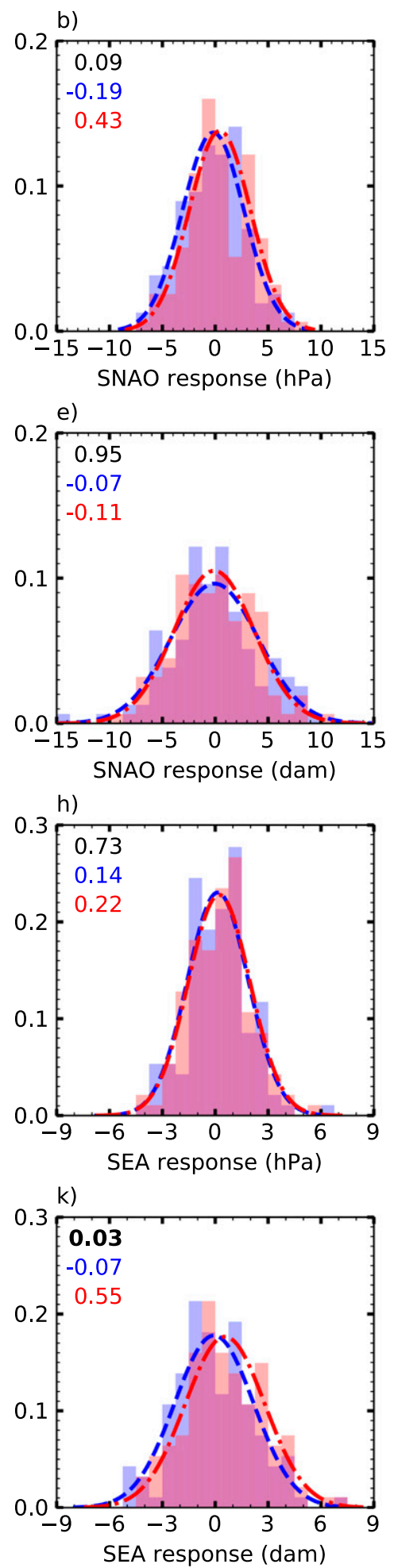

TRO
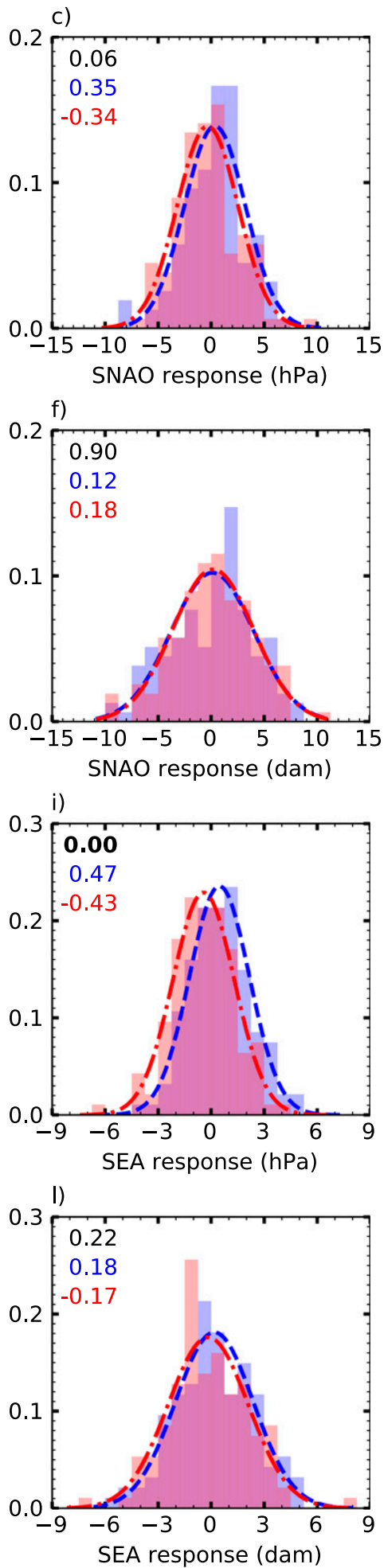

FIG. 7. Probability density functions of the (a)-(f) SNAO and (g)-(l) SEA pattern responses to (left) GLO SSTs, (center) ATL SSTs, and (right) TRO SSTs. Shown in (a)-(c) and (g)-(i) are the SNAO and SEA pattern responses defined for MSLP, respectively, and shown in (d)-(f) and (j)-(l) are the SNAO and SEA pattern responses defined for $500 \mathrm{hPa}$ geopotential height, respectively. The blue and red bars show the probabilities of the indicated SNAO and SEA pattern responses (calculated relative to the climatology in the CTL 
a)

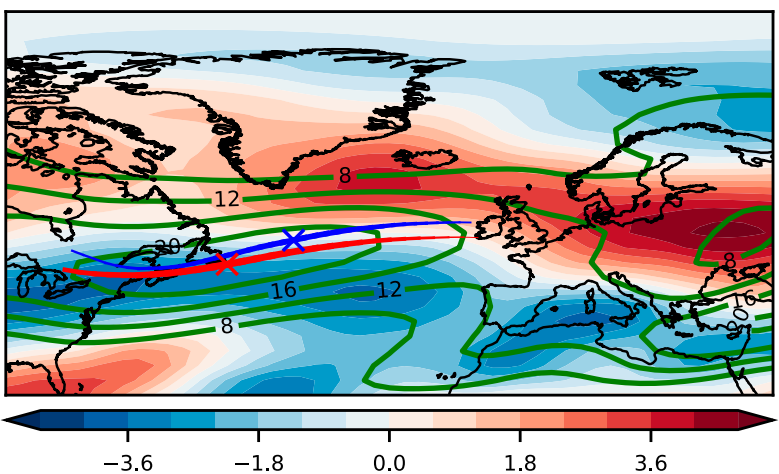

b)

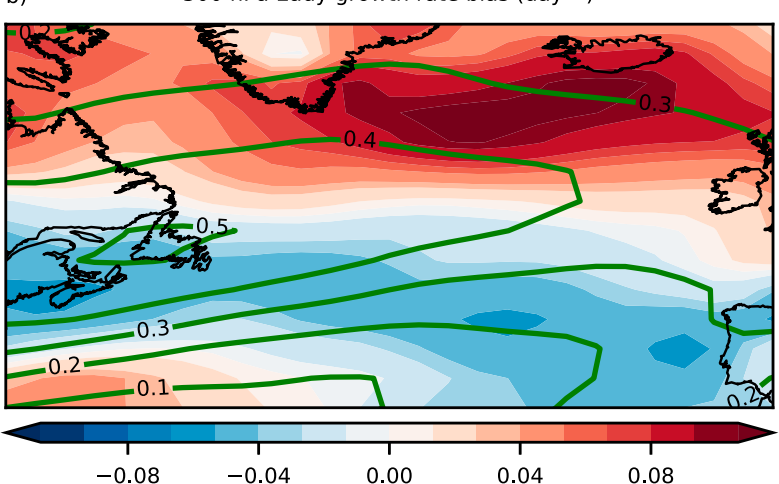

FIG. 8. (a) Summer $300 \mathrm{hPa}$ zonal wind bias in the CTL experiment and (b) $500 \mathrm{hPa}$ Eady growth-rate bias. Green contours show the climatologies in the NCEP-NCAR reanalysis for the period 1948-2016. The blue and red lines in (a) show the climatological latitudes of the $300 \mathrm{hPa}$ zonal wind maxima at the given longitudes for the CTL experiment and reanalysis, respectively. The thicknesses of the blue and red lines represent the magnitudes of the maxima at the given longitudes, scaled between 15.8 and $23.0 \mathrm{~m} \mathrm{~s}^{-1}$ (the range in maxima represented by the lines). The crosses show the climatological $300 \mathrm{hPa}$ zonal wind maxima across across the entire domain.

inherent nonlinearities, with, for example, evidence for nonlinearities in the relationship between tropical SSTs and tropical convection (Jiménez-Esteve and Domeisen 2019). Regardless, despite the possible influence of nonlinear processes in the extratropical North Atlantic, there is strong evidence that the robust extratropical response to GLO SSTs originates from the tropical North Atlantic region, with no clear mechanism for how nonlinear extratropical processes would feed back on these tropical processes. As noted, there is also growing evidence for the Northern Hemisphere tropics forcing the Northern Hemisphere extratropics in summer (Ding et al. 2011; Gastineau and Frankignoul 2015; Wulff et al. 2017; Thomson and Vallis 2018).

The overdominance of the SEA pattern in explaining summer atmospheric circulation variability and the fact that the significant responses in the model experiment project onto this mode of variability is of interest. The work of Palmer (1999) used dynamic theory to show how external forcing tends to act on the current dominant circulation patterns. In other words, the internal feedbacks that determine the natural variability of a dynamic feature of the climate system also determine its response to forcing (Shepherd 2014). Several examples of this behavior are documented in the literature (Chen and Plumb 2009; Hoskins and Woollings 2015; Mori et al. 2019). This highlights the importance of the model biases in our simulations and whether the responses are in fact dependent on them, since the dominant natural variability may govern the response to forcing. One could argue that given these biases and the model's tendency to shift between the opposite poles of the SEA pattern, whether the signal-to-noise ratio is actually reduced by not prescribing the optimum SST anomalies. Our SST anomalies are informed by the real-world and the observed relationship between the SNAO and SSTs. However, the model may actually have been most sensitive to SSTs that are related to the SEA pattern. This would be an interesting focus for future work. Alternatively, this theory could be tested using an AGCM (or multiple AGCMs) in which the SNAO is correctly simulated as the dominant mode of summer atmospheric variability. There also remains the possibility that while the SST anomalies are forced by the SNAO, they might feedback onto the SEA pattern rather than the SNAO, with Ossó et al. (2018) showing some observational evidence for oceanic forcing of the SEA pattern from spring to summer.

Although we have shown that the feedback from the ocean in forcing atmospheric anomalies could be an important component of the fully coupled response, it is difficult to interpret what atmosphere-only experiments could mean for real-world predictability (Bretherton and Battisti 2000). It remains to be seen just how important a role this component plays in the coupling.

experiment) in the COLD and WARM ensembles, respectively. The curves represent the Gaussian (normal) fit to the responses. The nodes used to calculate the SNAO and SEA pattern are shown by the green boxes in Fig. 4 and are described in section 4 . The numbers in each panel show the $p$ value of the difference in means of the COLD and WARM ensembles using a two-tailed $t$ test (top value; black), with bold text indicating where the difference is statistically significant at the $95 \%$ confidence level; the mean of the COLD ensemble (middle value; blue), and the mean of the WARM ensemble (bottom value; red). 

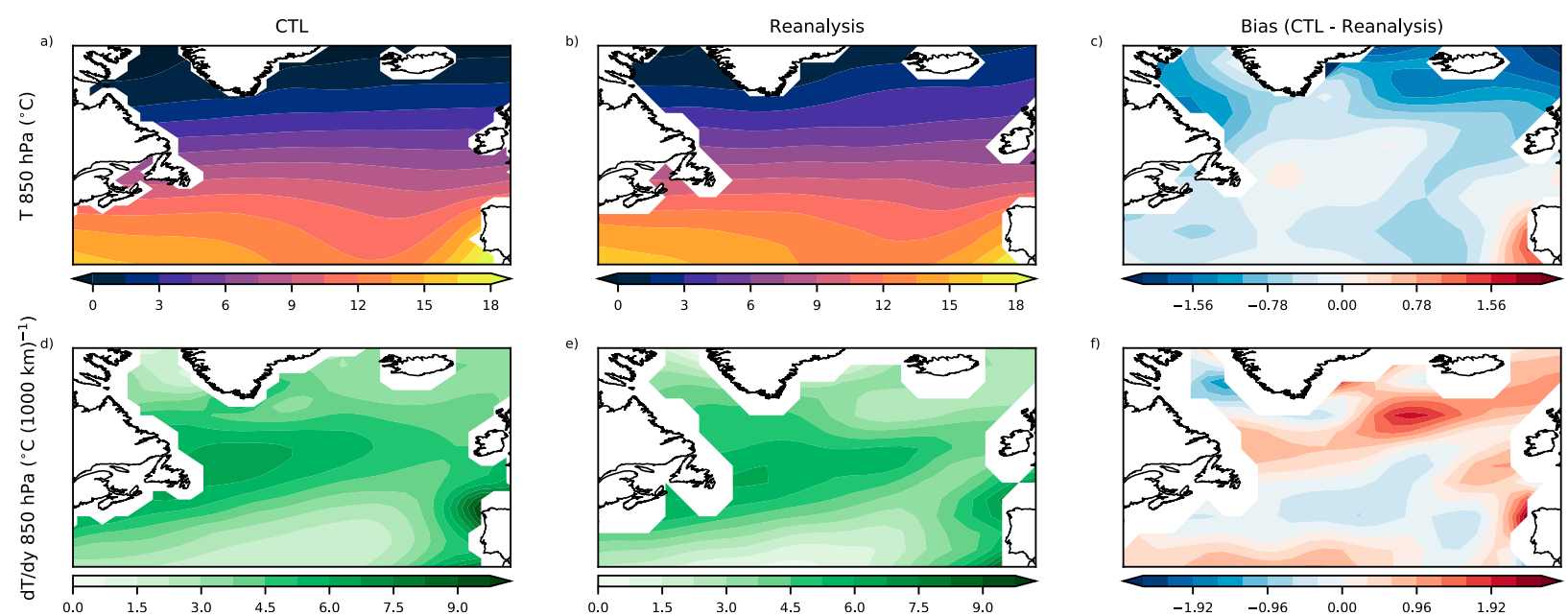

FIG. 9. Summer $850 \mathrm{hPa}$ temperature in (a) the CTL experiment, (b) the NCEP-NCAR reanalysis, and (c) their difference. (d)-(f) As in (a)-(c), but for the $850 \mathrm{hPa}$ meridional temperature gradient.

Further work could investigate the relative roles of these components in the full response, by nudging a coupled atmosphere-ocean model to the precursor spring oceanic anomalies related to the subsequent summer SNAO, and then allowing the coupled atmosphere-ocean model to freely evolve over the summer season. If a robust SNAOlike response were detected, then we could investigate the roles of the two components in generating a forced response. This would, however, be computationally expensive and may still require a large ensemble size to generate a robust response. It would also be likely that the kind of biases in these atmosphere-only experiments would be amplified in a coupled model, owing to biases in, for example, atmospheric feedbacks to oceanic forcing. The atmospheric forcing of the ocean could also be investigated using simple heat budget models for the upperocean mixed layer (Dong et al. 2013b; Duchez et al. 2016), using the atmospheric response to spring SST anomalies from our own simulations an input. This would give insight into whether the spring atmospheric response could force the ocean temperature tendency from spring to summer and the development of the North Atlantic SST tripole pattern. Such further research would help to determine the full role of the North Atlantic Ocean as a driver of summer circulation and help introduce more skill in summer seasonal forecasts over the NAE sector.

\section{Conclusions}

This study has revisited the question of whether the ocean, particularly SST anomalies in the North Atlantic, is capable of forcing robust atmospheric responses. The experiment design is such that we are able to disentangle influences from the extratropical and tropical North Atlantic domains. Other studies have tackled this separation of influences in a systematic way, often in an idealized model setup (Thomson and Vallis 2018), and it is extended here using an complex AGCM prescribed with realistic SST anomalies. The design is informed by observations and the hypothesis that the dominant mode of summer atmospheric circulation variability, the SNAO, can be forced by concurrent and correlated SST anomalies. While the relationship with SST anomalies in the North Atlantic can be at least partly understood through atmospheric forcing of the ocean, an important feedback from the ocean in forcing the atmosphere and SNAO variability has been suggested through observational analyses (Dong et al. 2013b), but not shown in a
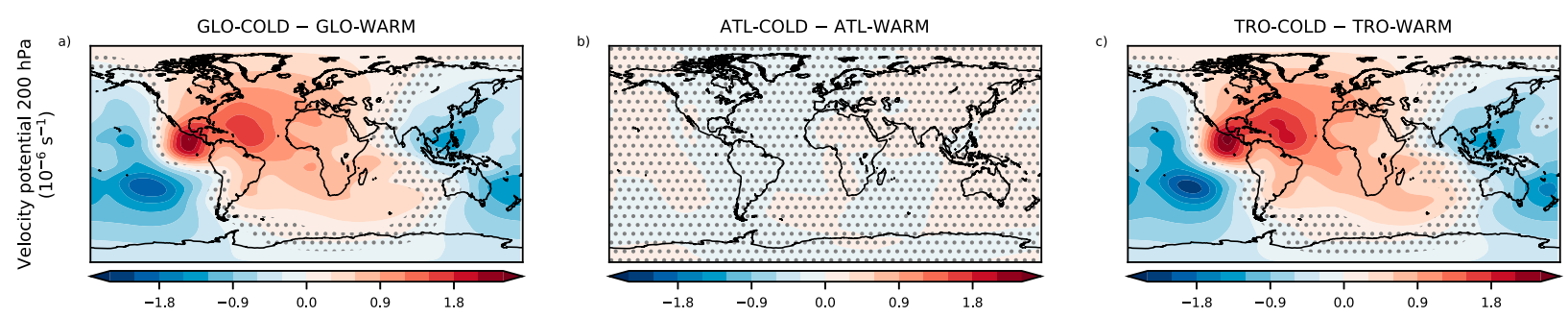

FIG. 10. As in Fig. 5, but for $200 \mathrm{hPa}$ velocity potential responses. 
modeling framework. Our results show that extratropical North Atlantic SSTs are capable of forcing robust circulation responses over the NAE sector, but the signal-to-noise ratio is predictably small, and any real-world response could actually be dominated by the response to remote tropical SSTs. Of particular interest is that the robust responses actually project onto the SEA pattern and not the SNAO pattern. Rather than being a null result, the fact that this might be explained by the representation of natural variability in the model used for the simulations is of great interest. It also could mean that the tropical influence on the extratropics is overestimated, or, in the case of the SEA-like response to tropical SSTs, that this forcing simply projects onto the SEA pattern and not the SNAO. These findings highlight an often overlooked but important aspect of such modeling studies: the potential influence of mean state and the related variability biases on model responses. Regardless of these complexities, the fact that the atmosphere responds to the North Atlantic in the summer is a valuable insight that requires further investigation. This result seems to offer encouragement that efforts to improve the representation of the atmospheric response to the ocean-through either improved model physics, higher-resolution simulations, or multimodel ensembles-could carry through to improved skill in summer seasonal forecasts.

Acknowledgments. This work was carried out while the lead author, JMO, was an employee of the University of Exeter. It was supported by the Natural Environment Research Council Grants NE/M006123/1 and NE/N018486/ 1. The HadGEM3-A simulations were performed on the ARCHER U.K. National Supercomputing Service. The output from these simulations required to replicate the analyses in this manuscript can be obtained at https:// doi.org/10.24378/exe.1484. The NCEP-NCAR reanalysis data can be obtained at https:/www.esrl.noaa.gov/psd/ data/gridded/data.ncep.reanalysis.html (Kalnay et al. 1996), the observed precipitation dataset, CRU TS4.02, can be found at http://www.cru.uea.ac.uk/data/ (Harris et al. 2014) and the HadISST SST dataset is at https:// www.metoffice.gov.uk/hadobs/hadisst/ (Rayner et al. 2003). Finally, the authors thank Professor Daniela Domeisen and one anonymous reviewer for thorough reviews and constructive feedback that helped to improve this manuscript.

\section{REFERENCES}

Alexander, M. A., K. H. Kilbourne, and J. A. Nye, 2014: Climate variability during warm and cold phases of the Atlantic Multidecadal Oscillation (AMO) 1871-2008. J. Mar. Syst., 133, 14-26, https://doi.org/10.1016/j.jmarsys.2013.07.017.

Ayarzagüena, B., S. Ineson, N. J. Dunstone, M. P. Baldwin, and A. A. Scaife, 2018: Intraseasonal effects of El Niño-Southern
Oscillation on North Atlantic climate. J. Climate, 31, 88618873, https://doi.org/10.1175/JCLI-D-18-0097.1.

Barnston, A. G., and R. E. Livezey, 1987: Classification, seasonality and persistence of low-frequency atmospheric circulation patterns. Mon. Wea. Rev., 115, 1083-1126, https://doi.org/ 10.1175/1520-0493(1987)115<1083:CSAPOL > 2.0.CO;2.

_ M. K. Tippett, M. Ranganathan, and M. L. L'Heureux, 2019: Deterministic skill of ENSO predictions from the North American multimodel ensemble. Climate Dyn., 53, 7215-7234, https://doi.org/10.1007/s00382-017-3603-3.

Bell, C. J., L. J. Gray, A. J. Charlton-Perez, M. M. Joshi, and A. A. Scaife, 2009: Stratospheric communication of El Niño teleconnections to European winter. J. Climate, 22, 4083-4096, https://doi.org/10.1175/2009JCLI2717.1.

Bladé, I., D. Fortuny, G. J. van Oldenborgh, and B. Liebmann, 2012: The summer North Atlantic Oscillation in CMIP3 models and related uncertainties in projected summer drying in Europe. J. Geophys. Res., 117, D16104, https://doi.org/ 10.1029/2012JD017816.

Branstator, G., and F. Selten, 2009: "Modes of variability" and climate change. J. Climate, 22, 2639-2658, https://doi.org/ 10.1175/2008JCLI2517.1.

Bretherton, C. S., and D. S. Battisti, 2000: An interpretation of the results from atmospheric general circulation models forced by the time history of the observed sea surface temperature distribution. Geophys. Res. Lett., 27, 767-770, https://doi.org/ 10.1029/1999GL010910.

Brönnimann, S., 2007: Impact of El Niño-Southern Oscillation on European climate. Rev. Geophys., 45, RG3003, https://doi.org/ 10.1029/2006RG000199.

Butler, A. H., and Coauthors, 2016: The Climate-System Historical Forecast Project: Do stratosphere-resolving models make better seasonal climate predictions in boreal winter? Quart. J. Roy. Meteor. Soc., 142, 1413-1427, https://doi.org/10.1002/ qj.2743.

Caian, M., T. Koenigk, R. Döscher, and A. Devasthale, 2018: An interannual link between Arctic sea-ice cover and the North Atlantic Oscillation. Climate Dyn., 50, 423-441, https://doi.org/ 10.1007/s00382-017-3618-9.

Chen, G., and R. A. Plumb, 2009: Quantifying the eddy feedback and the persistence of the zonal index in an idealized atmospheric model. J. Atmos. Sci., 66, 3707-3720, https://doi.org/ 10.1175/2009JAS3165.1.

Cohen, J., and Coauthors, 2014: Recent Arctic amplification and extreme mid-latitude weather. Nat. Geosci., 7, 627-637, https:// doi.org/10.1038/ngeo2234.

Collins, W. J., and Coauthors, 2011: Development and evaluation of an Earth-system model-HadGEM2. Geosci. Model Dev., 4, 1051-1075, https://doi.org/10.5194/gmd-4-1051-2011.

Deser, C., M. A. Alexander, S.-P. Xie, and A. S. Phillips, 2010: Sea surface temperature variability: Patterns and mechanisms. Annu. Rev. Mar. Sci., 2, 115-143, https://doi.org/10.1146/ annurev-marine-120408-151453.

Ding, Q., B. Wang, J. M. Wallace, and G. Branstator, 2011: Tropical-extratropical teleconnections in boreal summer: Observed interannual variability. J. Climate, 24, 1878-1896, https://doi.org/10.1175/2011JCLI3621.1.

Domeisen, D. I. V., A. H. Butler, K. Fröhlich, M. Bittner, W. A. Müller, and J. Baehr, 2015: Seasonal predictability over Europe arising from El Niño and stratospheric variability in the MPI-ESM seasonal prediction system. J. Climate, 28, 256271, https://doi.org/10.1175/JCLI-D-14-00207.1. 
Dong, B., R. Sutton, and T. Woollings, 2013a: The extreme European summer 2012. Bull. Amer. Meteor. Soc., 94, S28S32, https://doi.org/10.1175/BAMS-D-13-00085.1.

,,---1, and K. Hodges, 2013b: Variability of the North Atlantic summer storm track: Mechanisms and impacts on European climate. Environ. Res. Lett., 8, 034-037, https:// doi.org/10.1088/1748-9326/8/3/034037.

Duchez, A., and Coauthors, 2016: Drivers of exceptionally cold North Atlantic Ocean temperatures and their link to the 2015 European heat wave. Environ. Res. Lett., 11, 074004, https:// doi.org/10.1088/1748-9326/11/7/074004.

Dunstone, N., D. Smith, A. Scaife, L. Hermanson, R. Eade, N. Robinson, M. Andrews, and J. Knight, 2016: Skilful predictions of the winter North Atlantic Oscillation one year ahead. Nat. Geosci., 9, 809-814, https://doi.org/10.1038/ngeo2824.

—_ and Coauthors, 2018: Skilful seasonal predictions of summer European rainfall. Geophys. Res. Lett., 45, 3246-3254, https:// doi.org/10.1002/2017GL076337.

Eade, R., D. Smith, A. Scaife, E. Wallace, N. Dunstone, L. Hermanson, and N. Robinson, 2014: Do seasonal-to-decadal climate predictions underestimate the predictability of the real world? Geophys. Res. Lett., 41, 5620-5628, https://doi.org/10.1002/2014GL061146.

Folland, C. K., J. Knight, H. W. Linderholm, D. Fereday, S. Ineson, and J. W. Hurrell, 2009: The summer North Atlantic Oscillation: Past, present, and future. J. Climate, 22, 1082-1103, https://doi.org/ 10.1175/2008JCLI2459.1.

Gastineau, G., and C. Frankignoul, 2015: Influence of the North Atlantic SST variability on the atmospheric circulation during the twentieth century. J. Climate, 28, 1396-1416, https:// doi.org/10.1175/JCLI-D-14-00424.1.

Gulev, S. K., M. Latif, N. Keenlyside, W. Park, and K. P. Koltermann, 2013: North Atlantic Ocean control on surface heat flux on multidecadal timescales. Nature, 499, 464-467, https://doi.org/10.1038/nature12268.

Harris, I., P. Jones, T. Osborn, and D. Lister, 2014: Updated highresolution grids of monthly climatic observations-The CRU TS3.10 dataset. Int. J. Climatol., 34, 623-642, https://doi.org/ 10.1002/joc. 3711 .

Hodson, D. L. R., R. T. Sutton, C. Cassou, N. Keenlyside, Y. Okumura, and T. Zhou, 2010: Climate impacts of recent multidecadal changes in Atlantic Ocean sea surface temperature: A multimodel comparison. Climate Dyn., 34, 10411058, https://doi.org/10.1007/s00382-009-0571-2.

Hoskins, B. J., and D. J. Karoly, 1981: The steady linear response of a spherical atmosphere to thermal and orographic forcing. J. Atmos. Sci., 38, 1179-1196, https://doi.org/10.1175/15200469(1981)038<1179:TSLROA > 2.0.CO;2.

_ , and T. Ambrizzi, 1993: Rossby wave propagation on a realistic longitudinally varying flow. J. Atmos. Sci., 50, 1661-1671, https:// doi.org/10.1175/1520-0469(1993)050<1661:RWPOAR > 2.0.CO;2.

_ , and T. Woollings, 2015: Persistent extratropical regimes and climate extremes. Curr. Climate Change Rep., 1, 115-124, https://doi.org/10.1007/s40641-015-0020-8.

Ineson, S., A. A. Scaife, J. R. Knight, J. C. Manners, N. J. Dunstone, L. J. Gray, and J. D. Haigh, 2011: Solar forcing of winter climate variability in the Northern Hemisphere. Nat. Geosci., 4, 753-757, https://doi.org/10.1038/ngeo1282.

Jiménez-Esteve, B., and D. I. V. Domeisen, 2019: Nonlinearity in the North Pacific atmospheric response to a linear ENSO forcing. Geophys. Res. Lett., 46, 2271-2281, https://doi.org/ 10.1029/2018GL081226.
Kalnay, E., and Coauthors, 1996: The NCEP/NCAR 40-Year Reanalysis Project. Bull. Amer. Meteor. Soc., 77, 437-471, https://doi.org/ 10.1175/1520-0477(1996)077<0437:TNYRP>2.0.CO;2.

Knight, J. R., C. K. Folland, and A. A. Scaife, 2006: Climate impacts of the Atlantic multidecadal oscillation. Geophys. Res. Lett., 33, L17706, https://doi.org/10.1029/2006GL026242.

Kumar, A., M. Chen, and W. Wang, 2013: Understanding prediction skill of seasonal mean precipitation over the tropics. J. Climate, 26, 5674-5681, https://doi.org/10.1175/JCLI-D-1200731.1.

Kushnir, Y., W. A. Robinson, I. Bladé, N. M. J. Hall, S. Peng, and R. Sutton, 2002: Atmospheric GCM response to extratropical SST anomalies: Synthesis and evaluation. J. Climate, 15, 2233-2256, https://oi.org/ 10.1175/1520-0442(2002)015<2233:AGRTES >2.0.CO;2.

McKinnon, K. A., A. Rhines, M. Tingley, and P. Huybers, 2016 Long-lead predictions of eastern United States hot days from Pacific sea surface temperatures. Nat. Geosci., 9, 389-394, https://doi.org/10.1038/ngeo2687.

Minobe, S., A. Kuwano-Yoshida, N. Komori, S.-P. Xie, and R. J. Small, 2008: Influence of the Gulf Stream on the troposphere. Nature, 452, 206-209, https://doi.org/10.1038/nature06690.

Mori, M., Y. Kosaka, M. Watanabe, H. Nakamura, and M. Kimoto, 2019: A reconciled estimate of the influence of Arctic sea-ice loss on recent Eurasian cooling. Nat. Climate Change, 9, 123 129, https://doi.org/10.1038/s41558-018-0379-3.

Neddermann, N.-C., W. A. Müller, M. Dobrynin, A. Düsterhus, and J. Baehr, 2019: Seasonal predictability of European summer climate re-assessed. Climate Dyn., 53, 3039-3056, https://doi.org/10.1007/s00382-019-04678-4.

North, G. R., T. L. Bell, R. F. Cahalan, and F. J. Moeng, 1982: Sampling errors in the estimation of empirical orthogonal functions. Mon. Wea. Rev., 110, 699-706, https://doi.org/ 10.1175/1520-0493(1982)110<0699:SEITEO > 2.0.CO;2.

O'Reilly, C. H., T. Woollings, and L. Zanna, 2017: The dynamical influence of the Atlantic multidecadal oscillation on continental climate. J. Climate, 30, 7213-7230, https://doi.org/ 10.1175/JCLI-D-16-0345.1.

Ossó, A., R. Sutton, L. Shaffrey, and B. Dong, 2018: Observational evidence of European summer weather patterns predictable from spring. Proc. Natl. Acad. Sci. USA, 115, 59-63, https:// doi.org/10.1073/pnas.1713146114.

Palmer, T. N., 1999: A nonlinear dynamical perspective on climate prediction. J. Climate, 12, 575-591, https://doi.org/10.1175/ 1520-0442(1999)012<0575:ANDPOC >2.0.CO;2.

— , and D. L. T. Anderson, 1994: The prospects for seasonal forecasting-A review paper. Quart. J. Roy. Meteor. Soc., 120, 755-793, https://doi.org/10.1002/qj.49712051802.

Petrie, R. E., L. C. Shaffrey, and R. T. Sutton, 2015: Atmospheric impact of Arctic sea ice loss in a coupled ocean-atmosphere simulation. J. Climate, 28, 9606-9622, https://doi.org/10.1175/ JCLI-D-15-0316.1.

Rayner, N. A., D. E. Parker, E. B. Horton, C. K. Folland, L. V. Alexander, D. P. Rowell, E. C. Kent, and A. Kaplan, 2003: Global analyses of sea surface temperature, sea ice, and night marine air temperature since the late nineteenth century. J. Geophys. Res., 108, 4407, https://doi.org/10.1029/2002JD002670.

Rodwell, M. J., D. P. Rowell, and C. K. Folland, 1999: Oceanic forcing of the wintertime North Atlantic Oscillation and European climate. Nature, 398, 320-323, https://doi.org/10.1038/18648.

Sardeshmukh, P. D., and B. J. Hoskins, 1988: The generation of global rotational flow by steady idealized tropical divergence. J. Atmos. Sci., 45, 1228-1251, https://doi.org/10.1175/15200469(1988)045<1228:TGOGRF $>2.0$. CO;2. 
Scaife, A. A., and D. Smith, 2018: A signal-to-noise paradox in climate science. npj Climate Atmos. Sci., 1, 28, https://doi.org/ 10.1038/s41612-018-0038-4.

— , and Coauthors, 2011: Improved Atlantic winter blocking in a climate model. Geophys. Res. Lett., 38, L23703, https://oi.org/ 10.1029/2011GL049573.

- , S. Ineson, J. R. Knight, L. Gray, K. Kodera, and D. M. Smith, 2013: A mechanism for lagged North Atlantic climate response to solar variability. Geophys. Res. Lett., 40, 434-439, https://doi.org/10.1002/grl.50099.

_ European and North American winters. Geophys. Res. Lett., 41, 2514-2519, https://doi.org/10.1002/2014GL059637.

_- and Coauthors, 2017: Tropical rainfall, Rossby waves and regional winter climate predictions. Quart. J. Roy. Meteor. Soc., 143 (702), 1-11, https://doi.org/10.1002/qj.2910.

Schär, C., D. Lüthi, U. Beyerle, and E. Heise, 1999: The soilprecipitation feedback: A process study with a regional climate model. J. Climate, 12, 722-741, https://doi.org/10.1175/ 1520-0442(1999)012<0722:TSPFAP $>2.0 . C O ; 2$.

Screen, J. A., 2013: Influence of Arctic sea ice on European summer precipitation. Environ. Res. Lett., 8, 044015, https:// doi.org/10.1088/1748-9326/8/4/044015.

- I. Simmonds, C. Deser, and R. Tomas, 2013: The atmospheric response to three decades of observed Arctic sea ice loss. J. Climate, 26, 1230-1248, https://doi.org/10.1175/JCLI-D-12-00063.1.

Seneviratne, S. I., D. Lüthi, M. Litschi, and C. Schär, 2006: Landatmosphere coupling and climate change in Europe. Nature, 443, 205-209, https://doi.org/10.1038/nature05095.

T. Corti, E. L. Davin, M. Hirschi, E. B. Jaeger, I. Lehner, B. Orlowsky, and A. J. Teuling, 2010: Investigating soil moistureclimate interactions in a changing climate: A review. Earth-Sci. Rev., 99, 125-161, https://doi.org/10.1016/j.earscirev.2010.02.004.
Shepherd, T. G., 2014: Atmospheric circulation as a source of uncertainty in climate change projections. Nat. Geosci., 7, 703708, https://doi.org/10.1038/ngeo2253.

Sung, M.-K., S.-I. An, B.-M. Kim, and S.-H. Woo, 2014: A physical mechanism of the precipitation dipole in the western United States based on PDO-storm track relationship. Geophys. Res. Lett., 41, 4719-4726, https://doi.org/10.1002/2014GL060711.

Sutton, R. T., and D. L. R. Hodson, 2005: Atlantic Ocean forcing of North American and European summer climate. Science, 309, 115-118, https://doi.org/10.1126/science.1109496.

, and B. Dong, 2012: Atlantic Ocean influence on a shift in European climate in the 1990s. Nat. Geosci., 5, 788-792, https://doi.org/10.1038/ngeo1595.

Thomson, S. I., and G. K. Vallis, 2018: Atmospheric response to SST anomalies. Part II: Background-state dependence, teleconnections, and local effects in summer. J. Atmos. Sci., $\mathbf{7 5}$, 4125-4138, https://doi.org/10.1175/JAS-D-17-0298.1.

Walters, D., and Coauthors, 2017: The Met Office Unified Model Global Atmosphere 7.0/7.1 and JULES Global Land 7.0 configurations. Geosci. Model Dev., 12, 1909-1963, https:// doi.org/10.5194/gmd-12-1909-2019.

Woollings, T., B. Hoskins, M. Blackburn, D. Hassell, and K. Hodges, 2010: Storm track sensitivity to sea surface temperature resolution in a regional atmosphere model. Climate Dyn., 35, 341353, https://doi.org/10.1007/s00382-009-0554-3.

Wulff, C. O., R. J. Greatbatch, D. I. V. Domeisen, G. Gollan, and F. Hansen, 2017: Tropical forcing of the summer east Atlantic pattern. Geophys. Res. Lett., 44, 11 166-11173, https://doi.org/ 10.1002/2017GL075493.

Yang, S., and J. H. Christensen, 2012: Arctic sea ice reduction and European cold winters in CMIP5 climate change experiments. Geophys. Res. Lett., 39, L20707, https://doi.org/ 10.1029/2012GL053338. 